This document is confidential and is proprietary to the American Chemical Society and its authors. Do not copy or disclose without written permission. If you have received this item in error, notify the sender and delete all copies.

\title{
Systematic screening of deep eutectic solvents as sustainable separation media exemplified by the $\mathrm{CO} 2$ capture process
}

\begin{tabular}{|r|l|}
\hline Journal: & ACS Sustainable Chemistry \& Engineering \\
\hline Manuscript ID & sc-2020-02490c.R1 \\
\hline Manuscript Type: & Article \\
\hline Author: & n/a \\
\hline Complete List of Authors: & $\begin{array}{l}\text { Song, Zhen; Max-Planck-Institut fur Dynamik komplexer technischer } \\
\text { Systeme, process systems engineering } \\
\text { Hu, Xutao; East China University of Science and Technology, Chemical } \\
\text { engineering } \\
\text { Wu, Hongyi; Otto-von-Guericke-University Magdeburg Faculty of Process } \\
\text { and Systems Engineering } \\
\text { Mei, Mingcan; East China University of Science and Technology, School } \\
\text { of Chemical Engineering } \\
\text { Linke, Steffen; Otto von Guericke Universität Magdeburg, Chair for } \\
\text { Process Systems Engineering } \\
\text { Zhou, Teng; Max-Planck-Institut fur Dynamik komplexer technischer } \\
\text { Systeme, } \\
\text { Qi, Zhiwen; East China University of Science and Technology, State Key } \\
\text { Lab of Chemical Engineering } \\
\text { Sundmacher, Kai; Max-Planck-Institut fur Dynamik komplexer } \\
\text { technischer Systeme, Process Systems Engineering }\end{array}$ \\
\hline
\end{tabular}

\section{SCHOLARONE ${ }^{\text {m }}$ Manuscripts}




\section{ABSTRACT}

Although deep eutectic solvents (DESs) have attracted significant interest in various separation processes, rational methods guiding task-specific DES selection are still scarce. In this work, a systematic method for screening DESs as sustainable separation solvents is proposed and exemplified by the $\mathrm{CO}_{2}$ capture application. To achieve a large screening space, experimentally reported DESs are collected exhaustively from literature; for the most studied choline chloride $(\mathrm{ChCl})$ based DESs a correlation between their freezing point depression and COSMO-RS molecular descriptors of their hydrogen bond donors (HBDs) is established, which is applied to search a huge number of novel combinations of $\mathrm{ChCl}$ and $\mathrm{HBD}$ candidates for potential DESs. From the extended database combining experimental and potential DESs, promising $\mathrm{CO}_{2}$ absorbents are screened by integrating (a) the freezing point constraint according to the operating requirement, (b) the estimation of environment, health, and safety (EHS) impacts using quantitative structure-activity relationships methods, and (c) the prediction of thermodynamic properties by COSMO-RS. The practical solvent performance of the top DES candidates is finally studied by experiments, identifying $\mathrm{ChCl}$ : ethylenecyanohydrin (at mole ratios of $1: 2$ and 1:3) as very attractive $\mathrm{CO}_{2}$ absorbents.

KEYWORDS: deep eutectic solvent; freezing point depression correlation; EHS impact estimation; COSMO-RS; $\mathrm{CO}_{2}$ capture 


\section{INTRODUCTION}

Deep eutectic solvents (DESs) refer to systems obtained from mixing Lewis or Brønsted acids and bases, which present a much lower freezing point $\left(T_{\mathrm{f}}\right)$ than either of each individual component. ${ }^{1}$ Typical DESs are formed from an organic salt (e.g., ammonium or phosphonium salt) as hydrogen bond acceptor (HBA), and hydroxyl-, carboxyl-, or amino-containing organic alcohols or acids as hydrogen bond donor (HBD). ${ }^{2}$ In contrast to volatile organic compounds, DESs possess many attractive properties such as negligible vapor pressure, broad liquidus range, and easily tunable character, which render them as ionic liquid (IL) analogues. More interestingly, such mixture solvents offer two potential advantages over ILs: (1) in many cases, these solvents can be prepared by simply mixing their components in an appropriate ratio under mild heating, and thus avoid complex synthesis and purification steps as normally required for preparing ILs; (2) a large number of cheap and renewable compounds can be utilized as HBAs or HBDs of DESs, making this spectrum of solvents more affordable and sustainable. ${ }^{1-3}$ For these reasons, DESs have been recently thrust into the limelight as neoteric solvents for many separation processes, including gas absorption, ${ }^{4-6}$ liquid-liquid extraction, ${ }^{7-10}$ and natural product purification. ${ }^{11-13}$

Of central importance to realize a technically and economically feasible DES-based separation process is the selection of a suitable DES. Most previous studies relied on the experimental test of different combinations of DES components. However, this method is not only expensive and time-consuming, but also cannot ascertain the optimal DES system as a large variety of potential components and their different ratios theoretically result in an almost limitless solvent space. Several groups have utilized equations of state methods such as PCSAFT for modelling the phase behaviors of DES-containing systems. ${ }^{14,15}$ Nevertheless, these methods require a number of molecule-specific and mixing parameters fitted from experimental data, presenting a limited predictive capability for novel systems. Additionally, 
ab initio methods such as molecular dynamics and quantum chemical calculations have also been applied to offer useful insight into DES properties and their performances for certain separation tasks. ${ }^{16,17}$ However, such methods are highly expertise-dependent and computation-demanding, and are thus impractical for extensive DES screening. In this context, reliable methods that can guide the efficient screening of DESs are highly desirable.

Compared with the cases for conventional organic solvents and ILs, ${ }^{18-22}$ the theoretical screening or design of DESs for separations is still in its infancy. Hitherto, there are only a few DES screening studies which utilize the COSMO-RS method to fast evaluate the thermodynamic performances of a number of DESs. Bezold et al. employed COSMO-RS to screen DES-based solvent systems, that is, the stationary phase and mobile phase for chromatographic separation; the liquid-liquid equilibria of \{alkane + alcohol + DES $\}$ systems are first calculated, and thereafter the partition coefficients of different target solutes in the biphasic systems are estimated. ${ }^{24,25}$ Hadj-Kali and coworkers performed the DES screening for the denitrification of diesel and the cyclohexane-benzene separation by estimating the selectivity, capacity, and performance index at infinite dilution with COSMO-RS. ${ }^{26,27}$ In addition to these screening-oriented studies, several researchers also employed the COSMORS model for predicting and interpreting the thermodynamic properties of certain DESs and/or DES-involved mixtures. ${ }^{28-35}$ For instance, Aissaoui et al. evaluated four DESs for the dehydration of natural gas and interpreted the structural combination and water absorption mechanism combining the activity coefficient prediction, the $\sigma$-profile and $\sigma$-potential analyses using COSMO-RS; ${ }^{28}$ recently, the research group has integrated the COSMO-RS and molecular dynamic methods to study the $\mathrm{CO}_{2}$ solubility in seven DESs. ${ }^{29}$ Liu et al. evaluated and calibrated COSMO-RS for the prediction of $\mathrm{CO}_{2}$ solubility in DESs based on experimental data, and analyzed the $\mathrm{CO}_{2}$ absorption mechanism of DESs from analyzing the $\sigma$-profiles and interaction energies. ${ }^{35}$ Despite the progress made, these above studies in 
general only covered a small number of DES candidates that are either experimentally reported or hypothetically combined from widely used HBAs and HBDs (presuming their DES formation). In this sense, there is an urgent need for the development of DES screening method to be able to reasonably search optimal candidates over a much larger molecular space.

Besides suffering from a limited solvent search space, the previous screening studies also have not specifically considered the environmental, health, and safety (EHS) impacts of DES candidates. This is the case for many experimental DES studies as well, where the possible DES formation of different components and the application performance are mainly concentrated on while the EHS compatibility of DESs is usually taken for granted. However, such assumption is clearly unwarranted, especially when the DESs are not based on natural and sustainable components. ${ }^{36}$ For instance, Wen et al. studied the biodegradability of eight DESs, out of which only three show a theoretical oxygen demand of $60 \%$ or higher within 14 days (a general biodegradable threshold); ${ }^{37}$ several groups have also experimentally proved the toxicity and cytotoxicity of DESs. ${ }^{36}$ Therefore, to fulfill the potential of DESs as sustainable separation media, it is highly preferable to evaluate the EHS impacts of DESs in the early screening stage.

Taking account of the aforementioned aspects, a systematic method for screening DESs as separation solvent is proposed in the present work (see Figure 1 for the overall framework). The whole DES screening method consists of three main steps. The first step is the DES database collection and extension, aiming to overcome the limited solvent search space in previous DES screening. The experimentally reported DESs are exhaustively collected from literature, based on which a correlation between the freezing point depression $\left(\Delta T_{\mathrm{f}}\right)$ of DESs and the quantum chemical molecular descriptors of their components is explored for solvent database extension. The next step is the DES screening for a given separation task, which 
particularly evaluates the potential EHS impacts of DESs in addition to their thermodynamic properties. In the third step, experiments are carried out to validate the separation performances of the top candidates screened above. To demonstrate the proposed DES screening method, the $\mathrm{CO}_{2}$ capture process is taken as an illustrative case study.

\section{DES DATABASE COLLECTION AND EXTENSION}

\section{Collection of experimentally reported DESs}

DESs that have been experimentally reported are collected exhaustively from literature for two purposes: (1) such already existing ones can be first stored as a subset of the final database for DES screening; (2) through analyzing the data on these DESs, prediction methods for the eutectic behaviors between different components could be explored so that one can subsequently search over a larger space of novel HBA: HBD combinations for potential DESs.

As tabulated in Table S1 (Supporting Information), 461 experimentally reported DESs are collected after an exhaustive literature review (in this work, each unique combination of components and component ratios is treated as a distinct DES from the solvent screening point of view). To our best knowledge, this is the largest DES database available up to now. However, comparing with the huge variety of possible HBA: HBD combinations, the already covered ones are only the tip of the iceberg, which clearly highlights the importance of DES database extension. By reviewing the HBAs and HBDs separately, a majority of these collected DESs belong to the type III (i.e., a combination of a quaternary ammonium salt and an HBD) while a notable number of them formed by two non-salt compounds are out of the four types as classified by Smith et al. ${ }^{3}$ Overall, there are 80 HBAs and 142 HBDs involved for the 461 collected DESs (Table S2, Supporting Information). These HBAs and HBDs could be taken directly as candidate component pools for DES database extension. 


\section{$\Delta T_{\mathrm{f}}$ prediction of ChCl-based DESs}

The core issue for extending DES screening space is to determine whether a novel HBA: HBD combination can potentially present a eutectic behavior with $T_{\mathrm{f}}$ satisfying the operating requirement for a specific task. ${ }^{38}$ To this end, the most straightforward way is the prediction of solid-liquid equilibria (SLE). ${ }^{39,40}$ By quantifying the SLE curves (as illustrated in Figure 2), one can identify the $T_{\mathrm{f}}$ of the HBA: HBD mixture at different molar ratios, including the eutectic point $\left(T_{\mathrm{e}}\right)$ at the eutectic composition $\left(x_{\mathrm{e}}\right)$. However, the SLE prediction of DES systems is challenging because it requires experimental properties of components including melting temperature and enthalpy as well as an activity coefficient model for the liquid phase, which are often unavailable for potential DES components of interest. An expedient way to estimate the eutectic behavior between two components could be the prediction of freezing point depression $\left(\Delta T_{\mathrm{f}}\right){ }^{3}$ As shown in Figure $2, \Delta T_{f}$ denotes the difference between the ideally interpolated temperature at $x_{\mathrm{e}}\left(T_{\mathrm{f}, \mathrm{im}}\right)$ and the practical $T_{e}$. Once the $\Delta T_{f}$ for a given combination of components is predictable, its $T_{\mathrm{e}}$ can be in turn estimated with the knowledge of the $T_{\mathrm{f}}$ of components (i.e., $T_{\mathrm{f}, \mathrm{A}}$ and $\left.T_{\mathrm{f}, \mathrm{B}}\right)$ and the $x_{e}$. The $T_{\mathrm{e}}$ of one HBA: HBD combination, which is the lowest $T_{\mathrm{f}}$ it can reach, can be used to primarily check its applicability as solvent for a specific separation.

As the $\Delta T_{\mathrm{f}}$ of DESs is generally believed to be positively related to the interactions (often through hydrogen bond) between components, ${ }^{3}$ Abott et al. have recently proposed a $\Delta T_{\mathrm{f}}$ correlation with the enthalpy of hydrogen bond formation $\left(\Delta \mathrm{H}_{\mathrm{hb}}\right)$ on the basis of 13 choline chloride $(\mathrm{ChCl})$ based DESs. ${ }^{41}$ However, the obtained correlation could not be applied for general $\Delta T_{\mathrm{f}}$ prediction since the experimentally measured $\Delta \mathrm{H}_{\mathrm{hb}}$ is required while the correlation result is yet unsatisfying. From the predictive point of view, it is highly desirable to develop $\Delta T_{\mathrm{f}}$ models based on experimentally independent molecular descriptors and possessing better correlation performance. In this work, the third hydrogen bond (HB) 
moments HB_acc3 and HB_don3 in the COSMO-RS theory, which are important quantitative measures of HB acceptor and donor capacities of compounds, ${ }^{42,43}$ are introduced as molecular descriptors associated with HB interaction; moreover, to account for the potential spatial factor affecting HB formation, ${ }^{41,44}$ the descriptor of molecular volume is also considered. All these HB- and volume-related molecular descriptors of DES components can be readily obtained from COSMO-RS analysis. To explore whether such molecular descriptors can be applied for a more reliable $\Delta T_{\mathrm{f}}$ correlation, the $\Delta T_{\mathrm{f}}$ of the experimentally reported DESs are exhaustively retrieved. It is found that only a small portion of the DES studies have provided the SLE between DES components for $\Delta T_{\mathrm{f}}$ determination and most of these DES systems are based on the HBA of $\mathrm{ChCl} .{ }^{1,41,44-48}$ For this reason, this work only explores the $\Delta T_{\mathrm{f}}$ correlation with the COSMO-RS (implemented in COSMOthermX16) derived molecular descriptors for ChCl-based DESs in the following.

As summarized in Table S3 (Supporting Information), there are overall 35 different ChClbased DESs whose $\Delta T_{\mathrm{f}}$ can be determined from experimental SLE. Considering the HBAs in these DESs are identical, only the molecular descriptors of HBDs are tested for the $\Delta T_{\mathrm{f}}$ correlation. Based on a randomly selected regression set (31 data points), the best $\Delta T_{\mathrm{f}}$ correlation is obtained as a multilinear relationship (MLR) with the HB_don3, HB_acc3, and molecular volume $\left(\mathrm{V}_{\mathrm{COSMO}}\right)$ of HBDs:

$$
\Delta T_{f}=9.03 \times \mathrm{HB} \_ \text {don } 3+2.90 \times \mathrm{HB} \_ \text {acc } 3-0.23 \times \mathrm{V}_{\mathrm{COSMO}}+136.02
$$

The detailed statistical result of this MLR is tabulated in Table 1 and compared with other model options in Table S4 (Supporting Information). As seen, (1) all the three descriptors have a high $\mathrm{F}$-value and a low p-value $(<0.05)$, confirming that they all have great significance in the correlation; (2) the coefficient of determination $\left(\mathrm{R}^{2}\right)$ of the above MLR is 0.85 (much higher than the $\Delta \mathrm{H}_{\mathrm{hb}}$-based result ${ }^{41}$ ) with a close adjusted $\mathrm{R}^{2}$ of 0.83 ; (3) the variance inflation factor (VIF) analysis shows negligible multicollinearity between these three 
descriptors. From the coefficients of each term, the HB_don3 and HB_acc3 of HBD have a positive effect whereas its $\mathrm{V}_{\text {COSMO }}$ has a negative effect on the $\Delta T_{\mathrm{f}}$ of DES. This good correlation between $\Delta T_{\mathrm{f}}$ and the selected molecular descriptors of HBDs essentially validates the significance of $\mathrm{HB}$ in the formation of many DESs. Figure 3 compares the MLR correlated and experimentally determined $\Delta T_{\mathrm{f}}$ of these ChCl-based DESs. As seen, although the four ChCl-based DESs in the validation set are not used for correlating the MLR, the predicted $\Delta T_{\mathrm{f}}$ of them agrees reasonably with their experimental data, demonstrating the reliability of the obtained MLR. Moreover, the broad range of different HBD types (such as urea, phenols, fatty alcohols, sugars, mono- and poly-carboxylic acids) covered by the 35 DESs indicates a good generalization ability of the MLR for $\Delta T_{\mathrm{f}}$ correlation.

It is also worth mentioning that the $\mathrm{HB}$ _don3, $\mathrm{HB}$ _acc3, and $\mathrm{V}_{\mathrm{COSMO}}$ are empirically selected from different types of COSMO-RS derived molecular descriptors according to the potential mechanism of $\Delta T_{\mathrm{f}}$. However, when other larger descriptor datasets such as all the HB moments $^{42}$ or the area descriptors of the screening charge density $(\sigma \text {-profile })^{49,50}$ are tested (supported by the principle component analysis or partial least squares method), the best $\Delta T_{\mathrm{f}}$ correlation performances are almost at the same level as the present MLR; this finding also holds true if the nonlinear terms between $\mathrm{HB} \_$don3, $\mathrm{HB} \_$acc3, and $\mathrm{V}_{\mathrm{COSMO}}$ are tested in the correlation (Table S4, Supporting Information). These comparisons clearly demonstrate the rationality of the selected parameters for correlating the HB-related property of $\Delta T_{\mathrm{f}}$. Considering the remarkable simplicity and mechanism basis, the MLR based on HB_don3, HB_acc3, and $\mathrm{V}_{\mathrm{COSMO}}$ is thus presented here.

\section{Searching of potential ChCl-based DESs}

As already mentioned, the 461 experimentally reported DESs in Table S1 (Supporting Information) are still far less than the large number of possible HBA: HBD combinations. Therefore, from the screening point of view, it is highly desirable to extend the solvent 
database by including more potential DESs. For this purpose, the above MLR model for $\Delta T_{\mathrm{f}}$ is employed to estimate the eutectic behavior for a large number of novel combinations of $\mathrm{ChCl}$ with $\mathrm{HBD}$ candidates, thereby searching for potential ChCl-based DESs. In this work, all the HBDs involved in the experimentally reported DESs (Table S2, Supporting Information) and the conventional molecules in COSMObase (Ver. 1301, COSMOlogic $\mathrm{GmbH})$ are initially taken as the HBD candidate database, resulting in 7666 novel HBDs to be evaluated (Table S5, Supporting Information). Of course, one can introduce other molecular databases if more potential HBDs are desired for the DES database extension.

To screen out promising HBDs of ChCl-based DESs, two sets of empirical constraints are considered prior to the $\Delta T_{\mathrm{f}}$ estimation. First, to ensure a selected compound can practically act as HBD, a lower bound on the HB_don3 and an upper bound on the HB_acc3 are introduced. By analyzing the 35 experimentally reported ChCl-based DESs, this work sets these values as 1.63 and 12.61 , respectively. With these bounds, candidates with poor HB donor capacity or mainly featuring HB acceptor capacity could be discarded. Correspondingly, 1691 HBD candidates in the initial database are retained. Second, the boiling points of HBD candidates are constrained to be higher than $373.15 \mathrm{~K}$, thereby eliminating the highly volatile candidates that are not favorable from the perspective of facile preparation, operation safety, and thermal stability of potential DESs. Consequently, 1390 of the 1691 HBD candidates survived. Among the discarded candidates, some potential ones may be missed by these rigorous empirical constraints. With more understanding of DES properties in the future, such empirical constraints could be properly modified in the pre-screening.

Following the empirical pre-screening, the $\Delta T_{\mathrm{f}}$ of the combinations of $\mathrm{ChCl}$ with each of the 1390 remaining HBDs is estimated by the MLR model (that is, $1390 \mathrm{ChCl}$ : HBD combinations without considering the component ratios). However, as mentioned above, it is the $T_{\mathrm{e}}$ rather than the $\Delta T_{\mathrm{f}}$ that primarily determines the applicability of an HBA: HBD 
combination as solvent for a specific separation. ${ }^{38-40}$ Therefore, the $T_{\mathrm{e}}$ is further evaluated for the $1390 \mathrm{ChCl}$ : HBD combinations. In the case of different $\mathrm{ChCl}$ : $\mathrm{HBD}$ combinations, the $T_{\mathrm{f}}$ of $\mathrm{ChCl}$ is known $(575.15 \mathrm{~K})$ and those of HBD candidates can be obtained from either the COSMObase or other online databases (e.g., PubChem). Regarding the $x_{\mathrm{e}}$, there is still no reliable prediction method. However, it is found that all the 35 experimentally reported DESs based on $\mathrm{ChCl}$ have the molar ratio of HBA to HBD not higher than $1: 1$ (12 of 1:1, 2 of 1:1.5, 18 of $1: 2$, and 3 of 1:3). ${ }^{1,41,44-48}$ Considering that the $T_{\mathrm{f}}$ of components and the $\Delta T_{\mathrm{f}}$ are fixed for a given HBA: HBD combination while $\mathrm{ChCl}$ has a higher $T_{\mathrm{f}}$ than almost all the $1390 \mathrm{HBD}$ candidates, the larger HBA to HBD molar ratio at the $x_{\mathrm{e}}$ will lead to a higher $T_{\mathrm{e}}$. Thus, the maximum eutectic points $\left(T_{\mathrm{me}}\right)$ of different $\mathrm{ChCl}$ : $\mathrm{HBD}$ combinations can be estimated by assuming their $x_{\mathrm{e}}$ at the HBA: HBD molar ratio of 1:1 (as shown in Figure 2). The $T_{\mathrm{me}}$ can be used instead of $T_{\mathrm{e}}$ to check whether a $\mathrm{ChCl}$ : $\mathrm{HBD}$ combination can satisfy the operating temperature requirement for a specific separation process in DES screening. Table S6 (Supporting Information) ranks the $1390 \mathrm{ChCl}$ : HBD combinations in the increasing order of their $T_{\text {me }}$. From the table, one can readily identify a list of potential DESs according to different tasks, which can be combined with the experimentally reported DESs as an extended database for solvent screening.

\section{DES SCREENING}

In this section, the $\mathrm{CO}_{2}$ capture process is employed as a case study to illustrate the DES screening procedure for separation tasks. This process has been intensively studied in the past decades since $\mathrm{CO}_{2}$ is regarded as the most significant anthropogenic greenhouse gas and the major contributor to global warming. ${ }^{6,51}$ A number of studies have recently reported the $\mathrm{CO}_{2}$ solubility in DESs whereas extensive DES screening work on this process is yet scarce. ${ }^{52-57}$ 


\section{Screening by $T_{\mathrm{f}}$ constraint}

To obtain DESs that can be applied as room temperature $\mathrm{CO}_{2}$ absorbent, all the candidates in the combined database of Tables S1 and S6 (Supporting Information) are first screened by imposing a $T_{\mathrm{f}}$ constraint of below $298.15 \mathrm{~K}$. As a result, 241 of the 461 experimental DESs are retained, which are reported either having a $T_{\mathrm{f}}$ lower than $298.15 \mathrm{~K}$ or being liquid state at room temperature. Meanwhile, 158 of the 1390 potential ChCl: HBD combinations satisfy the $T_{\mathrm{f}}$ constraint as they have a $T_{\mathrm{me}}$ lower than $298.15 \mathrm{~K}$. The screened DES candidates in this step are tabulated in Table S7 (Supporting Information).

\section{Screening by EHS impacts}

To realize the potential of DESs as sustainable solvents, the EHS impacts of DESs are further considered after the screening by $T_{\mathrm{f}}$. As there is still no predictive method for the EHS impacts of DESs, such properties are estimated empirically from those of their individual components.

Regarding the HBDs involved in the DES candidates, the modern software package VEGA ${ }^{58}$ is first employed to evaluate five molecular properties concerning EHS: the persistence, the bioconcentration factor (BCF), mutagenicity, carcinogenicity, and toxicity. VEGA is a computational platform that incorporates a series of quantitative structure-activity relationship (QSAR) models for EHS-related properties of molecules. Simply inputted with the SMILES of molecules, these QSAR models can give the prediction on the EHS-related properties along with a reliability measure of the corresponding prediction. Generally, the prediction reliability of these models is divided into four levels namely experimental (i.e., experimental data available), good, moderate, and low, which is assessed from the applicability domain index for each prediction. For each of the five concerned properties, there is more than one QSAR method available in VEGA; this work selects all of them and their predictions are integrated to make the overall assessment. To be specific, by integrating the prediction result and 
reliability of different available models, each EHS-related property is classified into five grades as follows.

Grade 1 (green): consistent predictions obtained by different models with good reliability or experimental data available for negative result;

Grade 2 (purple): consistent predictions obtained by different models with only moderate or low reliability for negative result;

Grade 3 (blue): inconsistent predictions obtained by different models while negative result is obtained with good reliability by at least one model;

Grade 4 (yellow): inconsistent predictions obtained by different models while no negative result is obtained with good reliability by any model;

Grade 5 (red): consistent predictions obtained by different models or experimental data available for positive result.

In the above grades, the negative result refers to non-persistent, non-bioaccumulative, nonmutagenic, non-carcinogenic and non-toxic, respectively, whereas the positive result indicates the opposites.

For the overall 242 HBDs involved in the remaining DES candidates (Table S7, Supporting Information), the prediction results of the five properties by different QSAR models are detailed in Table S8 (Supporting Information). The grade table of the five properties for these HBDs is summarized in Table S9 (Supporting Information) and shown in Figure 4 with some representatives. In this work, the HBDs are considered to be potentially EHS-compatible only when all the five concerned properties are in the first three grades (marked in green, purple or blue) and otherwise are discarded. Correspondingly, 73 out of the 242 involved HBDs survived. To finally identify whether these 73 HBDs could be utilized as EHS-compatible DES components, they are further gone over in the PubChem database to eliminate other potential concerns such as flammability, air- and water-sensitivity. As a consequence, 56 of 
the 73 HBDs are retained.

For the salt HBAs involved in the DES candidates, the VEGA software is inapplicable because such salt-like compounds are generally not included for training the incorporated QSAR models. ${ }^{58}$ Therefore, only the EHS-impacts of non-salt HBAs, such as betaine, menthol, and $\mathrm{N}$-methylacetamide are estimated (also seen in Tables S8 - S9, Supporting Information). Besides, $\mathrm{ChCl}$, the most prevailing salt $\mathrm{HBA}$, is known as an extensively used pro-vitamin in food and other consumer products and has merits such as low cost and economic synthesis. ${ }^{39,48}$ Hence, $\mathrm{ChCl}$ is also selected as an EHS-compatible HBA. The other involved salt HBAs are not considered subsequently in this work due to their yet uncertain EHS properties.

By estimating the EHS properties of individual components as above, 36 experimentally reported DESs and 35 potential $\mathrm{ChCl}$ : $\mathrm{HBD}$ combinations are screened in this step with promising EHS-compatibility (Table S10, Supporting Information).

\section{Screening by thermodynamic properties}

\section{Fundamentals of thermodynamic screening}

Of central relevance to select DESs as separation solvent is predicting the thermodynamic properties of DES-containing systems. In this step, the COSMO-RS model is taken for this purpose as it has been demonstrated to deliver good qualitative and in some cases acceptable quantitative predictions on the activity coefficient of different solutes in DESs and phase equilibria of DES-containing systems such as $\{$ DES + alcohol/aromatic/sulfur- or nitrogencompound + alkane $\}.{ }^{24-35}$ Considering the introduction of the model is elaborated elsewhere, ${ }^{42}$ only the main features for understanding the prediction in this work are briefly addressed as follows.

Beyond characterizing molecules with different molecular descriptors (as used in Section 2), 
COSMO-RS is essentially a model for calculating thermodynamic equilibria of fluids and liquid mixtures. A standard COSMO-RS calculation requires only the $\sigma$-profiles of the involved compounds, which details the amount of surface with polarity $\sigma$ on the surface of a molecule. Based on interacting surfaces combining the $\sigma$-profile with a fast and accurate statistical thermodynamic treatment, the chemical potential of compound $i$ in a solvent or solvent mixture $S\left(\mu_{i}^{S}\right)$ can be derived and thus a variety of thermodynamic properties are obtainable. For instance, the Henry's law constant of a given solute $j$ in $S\left(H_{j}^{S}\right)$ can be calculated as:

$$
H_{j}^{S}=\frac{\left(\mu_{j}^{S, \infty}-\mu_{j}^{G a s}\right)}{R T}
$$

where $\mu_{j}^{S, \infty}$ and $\mu_{j}^{\text {Gas }}$ are the chemical potential of $j$ at infinite dilution in $S$ and in the ideal gas phase, respectively. For incompressible liquid state, $H_{j}^{S}$ is equivalent to:

$$
H_{j}^{S}=\gamma_{j}^{S, \infty} p_{j}^{0}
$$

where $\gamma_{j}^{S, \infty}$ refers to the infinite dilution activity coefficient of $j$ in $S$ and $p_{j}^{0}$ denotes the vapor pressure of pure solute $j$.

For the representation of DESs in COSMO-RS, the electroneutral mixture approach is selected as it has been proven to deliver comparable results with other possible approaches while being more convenient for DES screening. ${ }^{24,26,27}$ As an example, for a [cation][anion]: HBD $(m: n)$ DES, the COSMO-RS input is $m$ mole of cations, $m$ mole of anions, and $n$ mole of the HBD. In COSMO-RS calculation, all these constituents contribute to the total moles, which differ from the experimental definition ( $m$ mole of salt and $n$ mole of HBD). Therefore, COSMO-RS derived properties that depend on the definition of mole fraction have to be converted to ensure the same reference standard as used in experiments. For instance, the Henry's law constant of solute $j$ in the [cation][anion]: HBD $(m: n)$ DES derived from 
COSMO-RS ( $H_{j}^{\mathrm{COSMO}}$ ) can be converted to the experimentally based value $\left(H_{j}^{\exp }\right)$ as:

$$
H_{j}^{\text {exp }}=\frac{m+n}{2 m+n} H_{j}^{\text {COSMO }}
$$

For the $\mathrm{CO}_{2}$ capture case study, the absorption capacity (AC) and desorption easiness (DE) are employed as the thermodynamic criteria for DES screening, which are derived from the Henry's law constant as:

$$
\begin{aligned}
& A C=\frac{1}{H_{C O 2}^{298.15}} \times \frac{M W_{C O 2}}{M W_{D E S}} \\
& D E=\frac{H_{C O 2}^{328.15}}{H_{C O 2}^{298.15}}
\end{aligned}
$$

where $M W_{C O 2}$ and $M W_{D E S}$ are the molecular weights of $\mathrm{CO}_{2}$ and DES; $H_{\mathrm{CO} 2}^{298.15}$ and $H_{C O 2}^{328.15}$ represent the Henry's law constant of $\mathrm{CO}_{2}$ in DES at $298.15 \mathrm{~K}$ and $328.15 \mathrm{~K}$, respectively. Similar criteria have been demonstrated to be effective for screening ILs with promising mass-based gas absorption performances and thus are also utilized here for DES screening. ${ }^{59,60}$ In the following, all the involved COSMO-RS calculations are performed under the parameterization of BP_TZVP_16.ctd in COSMOthermX16.

\section{Results of thermodynamic screening}

Prior to thermodynamic screening, the predictive reliability of COSMO-RS for $\mathrm{CO}_{2}$-in-DES systems is evaluated by comparing experimentally reported $H_{\mathrm{CO} 2}$ with their COSMO-RS predicted counterparts (Table S11, Supporting Information). ${ }^{52-54}$ Nine HBA: HBD combinations are involved in the evaluation, covering three different HBAs and seven different HBDs. For these combinations, $H_{\mathrm{CO} 2}$ of different HBA: HBD molar ratios $(1: 2-5)$ and within a wide temperature range $(293.15 \mathrm{~K}-323.15 \mathrm{~K})$ are involved. As compared in Figure 5, despite some reasonable deviations, the COSMO-RS predicted $\mathrm{H}_{\mathrm{CO} 2}$ are in good qualitative agreement with the experimental results, which can be suggested by the relatively 
high $R^{2}(0.83)$. Moreover, the quantitative prediction performance of COSMO-RS for $H_{C O 2}$ is estimated through the absolute average relative deviation (AARD):

$$
A A R D=\frac{1}{N D} \sum_{1}^{N D}\left|\frac{H_{\mathrm{CO} 2}^{\exp }-H_{\mathrm{CO} 2}^{\mathrm{cal}}}{H_{\mathrm{CO} 2}^{\exp }}\right|
$$

where $H_{\mathrm{CO} 2}^{\text {exp }}$ and $H_{\mathrm{CO} 2}^{\mathrm{cal}}$ are the experimental and calculated $H_{\mathrm{CO} 2}$, respectively; $N D$ is the number of data points. Although the AARD is $43.60 \%$ for the $H_{\mathrm{CO} 2}$ directly predicted by COSMO-RS, it is notably decreased to $8.65 \%$ after calibrated by the linear correlation (see Table S11, Supporting Information). Considering the fully predictive character of COSMORS, such a quantitative performance after calibration is quite acceptable, which agrees with the finding based on 502 data of $\mathrm{CO}_{2}$ solubility. Therefore, the COSMO-RS model assisted by the obtained calibration relationship can be applied as a suitable thermodynamic method for the DES screening for the $\mathrm{CO}_{2}$ capture case study.

After the COSMO-RS benchmarking, the AC and DE of the DES candidates remained after the EHS screening are predicted by COSMO-RS (combining with the linear calibration). For evaluating the $\mathrm{AC}$ and $\mathrm{DE}$ of the potential $\mathrm{ChCl}$ : $\mathrm{HBD}$ combinations, three most common HBA: HBD molar ratios of ChCl-based DESs namely 1:1, 1:2, and 1:3 are tested. Figure 6 shows the obtained AC and DE of the involved DES candidates (see detailed data in Table S12, Supporting Information). As both higher $\mathrm{AC}$ and $\mathrm{DE}$ are favorable for the $\mathrm{CO}_{2}$ capture, only the candidates simultaneously ranking top $50 \%$ in these two criteria are screened out in this step. The corresponding lower bounds (lb) for the AC and DE are found to be $1.20 \times 10^{-3}$ and 1.45 , respectively. Consequently, 10 experimentally reported and 34 potential ChCl-based DESs are retained in the upper right region in Figure 6. To evaluate their overall suitability for $\mathrm{CO}_{2}$ capture, the $\mathrm{AC}$ and $\mathrm{DE}$ of them are multiplied. According to the ranking of $\mathrm{AC} \times \mathrm{DE}$ (Table 2), only two of the top 10 candidates are experimentally reported DESs while the others are all potential ones first suggested in this work. The much larger number of potential 
ChCl-based DESs satisfying the lower bounds for AC and DE (Figure 5) and ranking top in $\mathrm{AC} \times \mathrm{DE}($ Table 2) demonstrates the significance of searching novel DESs beyond the experimentally reported ones.

\section{EXPERIMENTAL VALIDATION}

From the above screening, the first DES with the highest $\mathrm{AC} \times \mathrm{DE}$ is $\mathrm{ChCl}$ : urea (1:2). This DES has already been experimentally proven to possess higher $\mathrm{CO}_{2}$ capacity than DESs like $\mathrm{ChCl}$ : glycerol (1:2) and $\mathrm{ChCl}$ : ethylene glycol (1:2), which are also comparable to some $[\mathrm{Bmim}]$-based ionic liquids paired with anions $\left[\mathrm{PF}_{6}\right]^{-},\left[\mathrm{BF}_{4}\right]^{-},[\mathrm{DCA}]^{-}$, and $\left[\mathrm{Tf}_{2} \mathrm{~N}\right]^{-} .55$ Such result could well suggest the reliability of the proposed DES screening method for the case study. Nevertheless, to validate that promising potential $\mathrm{ChCl}$ : HBD DESs are also identified, experiments for the $\mathrm{ChCl}$ : ethylenecyanohydrin combinations that rank from second to fourth in Table 2, are carried out.

Before the $\mathrm{CO}_{2}$ absorption experiments, the $\mathrm{ChCl}$ : ethylenecyanohydrin combinations $(1: 1$, 1:2, and 1:3) are prepared accordingly. $\mathrm{ChCl}(\geq 99 \mathrm{wt} \%$, purchased from Acros) is pretreated under vacuum drying at $80^{\circ} \mathrm{C}$ for $24 \mathrm{~h}$ before use; ethylenecyanohydrin ( $\geq 99 \mathrm{wt} \%$, purchased from Adamas) is used as received. In a typical run, appropriate amounts of $\mathrm{ChCl}$ and ethylenecyanohydrin, weighed by a Sartorius BSA224S-CW balance $( \pm 0.0001 \mathrm{~g})$, are mixed according to their molar ratios. The mixture is then heated to $323.15 \mathrm{~K}$ and stirred for $3 \mathrm{~h}$ to ensure the complete mixing of the two components. Afterwards, the mixture is cooled down to room temperature and inspected visually to check the formation of DESs. Following such a preparation procedure, a clear homogenous liquid is obtained for the $\mathrm{ChCl}$ : ethylenecyanohydrin combinations (1:2 and 1:3) whereas a cloudy mixture is observed for the $\mathrm{ChCl}$ : ethylenecyanohydrin (1:1). The reason why $\mathrm{ChCl}$ : ethylenecyanohydrin (1:1) doesn't form a homogeneous liquid can be understood as follows: for pre-screening potential HBDs 
by the $T_{\mathrm{f}}$ constraint, the $T_{\mathrm{me}}$ is estimated by assuming the $x_{\mathrm{e}}$ of $\mathrm{ChCl}$ : HBD combinations at the mole ratio of $1: 1$; however, for a specific $\mathrm{ChCl}$ : $\mathrm{HBD}$ combination (e.g.; $\mathrm{ChCl}$ : ethylenecyanohydrin), it is likely that the practical $x_{\mathrm{e}}$ locates at a smaller molar ratio $(<1: 1)$, which will lead to the $T_{\mathrm{e}}$ of the binary system lower than $T_{\mathrm{me}}$ but in turn bring about a higher freezing point of the mixture at 1:1 (as illustrated in Figure 2). Subsequently, the $\mathrm{CO}_{2}$ absorption experiments are only performed for the $\mathrm{ChCl}$ : ethylenecyanohydrin (1:2 and 1:3).

The pressure drop method, as introduced elaborately in our earlier work, ${ }^{17}$ is employed to determine the $\mathrm{CO}_{2}$ solubility in the DESs under pressure below $1500 \mathrm{kPa}$ at $298.15 \mathrm{~K}$ and 328.15 K. The obtained results in molarity and molality are given in Table S13 (Supporting Information). As seen in Figure 7, the $\mathrm{CO}_{2}$ solubility in the DESs grows almost linearly with increasing pressure and the extrapolation line basically passes through the origin of the coordinate, indicating a physical absorption of $\mathrm{CO}_{2}$ in these solvents. Moreover, the $\mathrm{CO}_{2}$ solubility in $\mathrm{ChCl}$ : ethylenecyanohydrin at the molar ratio of 1:2 is higher than that at the molar ratio of $1: 3$ under the same conditions and increasing the temperature from $298.15 \mathrm{~K}$ to $328.15 \mathrm{~K}$ notably decreases the $\mathrm{CO}_{2}$ solubility in both two cases. Such experimental results correspond well to the COSMO-RS derived AC and DE. Based on the measured solubility, the molality based Henry's law constant $\left(H_{\mathrm{m}}\right)$ of $\mathrm{CO}_{2}$ in the two DESs is calculated and compared to those in previously reported DESs ${ }^{52-57}$ and in some typical ionic liquids ${ }^{61,62}$ and commercial physical absorbents. ${ }^{63-65}$ As seen in Table 3, the $H_{\mathrm{m}}$ of $\mathrm{CO}_{2}$ in the studied DESs at 298.15 $\mathrm{K}$ is lower than that in $\mathrm{ChCl}$ : urea (1:2), $\mathrm{ChCl}$ : glycerol (1:2), and $\mathrm{ChCl}$ : ethylene glycol (1:2) at $303.15 \mathrm{~K}$, and is even lower than that in the other HBA: HBD combinations at 293.15 K. The low level of $H_{\mathrm{m}}$ of the studied DESs also holds when comparing to the cases of typical ionic liquids and commercial physical absorbents. Such comparisons well demonstrate the satisfactory $\mathrm{CO}_{2}$ absorption capacity of $\mathrm{ChCl}$ : ethylenecyanohydrin (1:2 and 1:3). Combining the potential EHS-compatibility, the DESs identified here are indeed attractive 
$\mathrm{CO}_{2}$ absorbents. It is worth mentioning that only the three common HBA: HBD molar ratios for ChCl-based DESs are tested here for the validation purpose; however, from the application point of view, further optimization potential could be expected by fine-tuning the molar ratio of this DES.

\section{CONCLUSION}

The systematic screening of DESs as sustainable separation solvent is presented in this work taking the $\mathrm{CO}_{2}$ capture process as an illustrative example. A database of 461 experimentally reported DESs is built and a reliable MLR correlation between the $\Delta T_{\mathrm{f}}$ of ChCl-based DESs and the $\mathrm{HB} \_$don3, $\mathrm{HB} \_$acc3, and $\mathrm{V}_{\mathrm{COSMO}}$ of their HBDs is established. Based on the obtained $\Delta T_{\mathrm{f}}$ correlation, potential ChCl-based DESs are searched over novel combinations with 7666 HBDs from experimental and COSMO-RS molecular database, which are combined with the experimental DESs as an extended database for DES screening. Illustrated by the $\mathrm{CO}_{2}$ capture case study, promising DES candidates are identified after screening by $T_{\mathrm{f}}$ constraint, potential EHS impacts, and thermodynamic properties. The top potential DES candidates, $\mathrm{ChCl}$ : ethylenecyanohydrin $(1: 2,1: 3)$, are experimentally demonstrated to have encouraging $\mathrm{CO}_{2}$ absorption performance. Beyond the case study, the extended DES database and the screening method could be easily applied to support the selection of DESs for other separation applications. In future work, with more experimental data available, the $\Delta T_{\mathrm{f}}$ correlation model can be further extended, for example, to cover other types of HBAs in addition to $\mathrm{ChCl}$, thereby enabling the search of more diverse DESs. 


\begin{abstract}
ASSOCIATED CONTENT
The Supporting Information is available free of charge on the ACS Publications Website at DOI:***.

Experimental DESs database collected from literature; HBAs and HBDs involved in experimental DES database; $35 \mathrm{ChCl}$-based DESs for $\Delta T_{\mathrm{f}}$ correlation; statistical comparison of different model options for $\Delta T_{\mathrm{f}}$; novel HBDs considered in the initial database; 1390 potential ChCl-based DESs in the increasing order of estimated $\mathrm{T}_{\mathrm{me}}$; DES candidates screened after imposing $T_{\mathrm{f}}$ constraint; predicted EHS-relevant properties for the involved HBDs and HBAs; grade table of the five EHS-relevant properties for the involved HBDs and HBAs; DES candidates screened after EHS impacts estimation; comparison of experimental and COSMO-RS predicted $H_{x}$ of $\mathrm{CO}_{2}$ in DESs; predicted AC and DE for DES screening; experimentally determined $\mathrm{CO}_{2}$ solubility in the studied DESs (XLSX).
\end{abstract}

\title{
ACKNOWLEDGEMENTS
}

The authors gratefully acknowledge the support of the Sino-German joint research project leaded by Deutsche Forschungsgemeinshaft (DFG) and National Natural Science Foundation of China (NSFC) under the grants SU 189/9-1 and 21861132019, respectively. 


\section{REFERENCE}

1. Abbott, A. P.; Boothby, D.; Capper, G.; Davies, D. L.; Rasheed, R. K. Deep eutectic solvents formed between choline chloride and carboxylic acids: versatile alternatives to ionic liquids. J. Am. Chem. Soc. 2004, 126, 9142-9147.

2. Zhang, Q. H.; Vigier, K. D.; Royer, S.; Jerome, F. Deep eutectic solvents: syntheses, properties and applications. Chem. Soc. Rev. 2012, 41, 7108-7146.

3. Smith, E. L.; Abbott, A. P.; Ryder, K. S. Deep eutectic solvents (DESs) and their applications. Chem. Rev. 2014, 114, 11060-11082.

4. Sze, L. L.; Pandey, S.; Ravula, S.; Pandey, S.; Zhao, H.; Baker, G. A.; Baker, S. N. Ternary deep eutectic solvents tasked for carbon dioxide capture. ACS Sustain. Chem. Eng. 2014, 2, 2117-2123.

5. Zhong, F. Y.; Zhou, L.; Shen, J.; Liu, Y.; Fan, J. P.; Huang, K. Rational design of azolebased deep eutectic solvents for highly efficient and reversible capture of ammonia. ACS Sustain. Chem. Eng. 2019, 7, 14170-14179.

6. Sarmad, S.; Mikkola, J. P.; Ji, X. Carbon dioxide capture with ionic liquids and deep eutectic solvents: a new generation of sorbents. ChemSusChem 2017, 10, 324-352.

7. Gilmore, M.; McCourt, E. N.; Connolly, F.; Nockemann, P.; Swadźba-Kwaśny, M.; Holbrey, J. D. Hydrophobic deep eutectic solvents incorporating trioctylphosphine oxide: advanced liquid extractants. ACS Sustain. Chem. Eng. 2018, 6, 17323-17332.

8. Bezold, F.; Minceva, M. Liquid-liquid equilibria of n-heptane, methanol and deep eutectic solvents composed of carboxylic acid and monocyclic terpenes. Fluid Phase Equilibr. 2018, 477, 98-106.

9. Larriba, M.; Ayuso, M.; Navarro, P.; Delgado-Mellado, N.; Gonzalez-Miquel, M.; García, J.; Rodríguez, F. Choline chloride-based deep eutectic solvents in the dearomatization of gasolines. ACS Sustain. Chem. Eng. 2018, 6, 1039-1047.

10. Gouveia, A. S.; Oliveira, F. S.; Kurnia, K. A.; Marrucho, I. M. Deep eutectic solvents as azeotrope breakers: liquid-liquid extraction and COSMO-RS prediction. ACS Sustain. Chem. Eng. 2016, 4, 5640-5650.

11. Abbott, A. P.; Cullis, P. M.; Gibson, M. J.; Harris, R. C.; Raven, E. Extraction of glycerol from biodiesel into a eutectic based ionic liquid. Green Chem. 2007, 9, 868-872.

12. Rodríguez-Llorente, D.; Bengoa, A.; Pascual-Muñoz, G.; Navarro, P.; Águeda, V. I.; Delgado, J. A.; Álvarez-Torrellas, S.; García, J.; Larriba, M. Sustainable recovery of volatile fatty acids from aqueous solutions using terpenoids and eutectic solvents. ACS Sustain. Chem. Eng. 2019, 7, 16786-16794. 
13. Wan Mahmood, W. M. A.; Lorwirachsutee, A.; Theodoropoulos, C.; Gonzalez-Miquel, M. Polyol-Based deep eutectic solvents for extraction of natural polyphenolic antioxidants from chlorella vulgaris. ACS Sustain. Chem. Eng. 2019, 7, 5018-5026.

14. Pontes, P. V.; Crespo, E. A.; Martins, M. A.; Silva, L. P.; Neves, C. M.; Maximo, G. J.; Hubinger, M. D.; Batista, E.; Pinho, S. P.; Coutinho, J. A.P.; Sadowski, G.; Held, C. Measurement and PC-SAFT modeling of solid-liquid equilibrium of deep eutectic solvents of quaternary ammonium chlorides and carboxylic acids. Fluid Phase Equilibr. 2017, $448,69-80$.

15. Dietz, C. H.; van Osch, D. J.; Kroon, M. C.; Sadowski, G.; van Sint Annaland, M.; Gallucci, F.; Zubeir, L. F.; Held, C. PC-SAFT modeling of $\mathrm{CO} 2$ solubilities in hydrophobic deep eutectic solvents. Fluid Phase Equilibr. 2017, 448, 94-98.

16. Wagle, D. V.; Zhao, H.; Deakyne, C. A.; Baker, G. A. Quantum chemical evaluation of deep eutectic solvents for the extractive desulfurization of fuel. ACS Sustain. Chem. Eng. 2018, 6, 7525-7531.

17. Wang, J.; Cheng, H.; Song, Z.; Chen, L.; Deng, L.; Qi, Z. Carbon dioxide solubility in phosphonium-based deep eutectic solvents: an experimental and molecular dynamics study. Ind. Eng. Chem. Res. 2019, 58, 17514-17523.

18. Zhou, T.; Song, Z.; Zhang, X.; Gani, R.; Sundmacher, K. Optimal solvent design for extractive distillation processes: a multiobjective optimization-based hierarchical framework. Ind. Eng. Chem. Res. 2019, 58, 5777-5786.

19. Song, Z.; Zhou, T.; Zhang, J.; Cheng, H.; Chen, L.; Qi, Z. Screening of ionic liquids for solvent-sensitive extraction - with deep desulfurization as an example. Chem. Eng. Sci. 2015, 129, 69-77.

20. Liu, X.; Huang, Y.; Zhao, Y.; Gani, R.; Zhang, X.; Zhang, S. Ionic liquid design and process simulation for decarbonization of shale gas. Ind. Eng. Chem. Res. 2016, 55, 59315944.

21. Song, Z.; Zhang, C.; Qi, Z.; Zhou, T.; Sundmacher, K. Computer-aided design of ionic liquids as solvents for extractive desulfurization. AIChE J. 2018, 64, 1013-1025.

22. Song, Z.; Hu, X.; Zhou, Y.; Zhou, T.; Qi, Z.; Sundmacher, K. Rational design of double salt ionic liquids as extraction solvents: separation of thiophene/n-octane as example. AIChE J. 2019, 65, No. e16625.

23. Silva, L. P.; Fernandez, L.; Conceição, J. H.; Martins, M. A.; Sosa, A.; Ortega, J.; Pinho, S. P.; Coutinho, J. A. Design and characterization of sugar-based deep eutectic solvents 
using conductor-like screening model for real solvents. ACS Sustain. Chem. Eng. 2018, 6, 10724-10734.

24. Bezold, F.; Weinberger, M. E.; Minceva, M. Assessing solute partitioning in deep eutectic solvent-based biphasic systems using the predictive thermodynamic model COSMO-RS. Fluid Phase Equilibr. 2017, 437, 23-33.

25. Bezold, F.; Weinberger, M. E.; Minceva, M. Computational solvent system screening for the separation of tocopherols with centrifugal partition chromatography using deep eutectic solvent-based biphasic systems. J. Chromatogr. A 2017, 1491, 153-158.

26. Hizaddin, H. F.; Ramalingam, A.; Hashim, M. A.; Hadj-Kali, M. K. Evaluating the performance of deep eutectic solvents for use in extractive denitrification of liquid fuels by the conductor-like screening model for real solvents. J. Chem. Eng. Data 2014, 59, 3470-3487.

27. Salleh, Z.; Wazeer, I.; Mulyono, S.; El-blidi, L.; Hashim, M. A.; Hadj-Kali, M. K. Efficient removal of benzene from cyclohexane-benzene mixtures using deep eutectic solvents-COSMO-RS screening and experimental validation. J. Chem. Thermodyn. 2017, $104,33-44$.

28. Aissaoui, T.; AlNashef, I. M.; Benguerba, Y. Dehydration of natural gas using choline chloride based deep eutectic solvents: COSMO-RS prediction. J. Nat. Gas Sci. Eng. 2016, $30,571-577$.

29. Alioui, O.; Benguerba, Y.; Alnashef, I. M. Investigation of the CO2-solubility in deep eutectic solvents using COSMO-RS and molecular dynamics methods. J. Mol. Liq. 2020, $307,113005$.

30. Mulyono, S.; Hizaddin, H. F.; Alnashef, I. M.; Hashim, M. A.; Fakeeha, A. H.; Hadj-Kali, M. K. Separation of BTEX aromatics from n-octane using a (tetrabutylammonium bromide + sulfolane) deep eutectic solvent-experiments and COSMO-RS prediction. RSC Adv. 2014, 4, 17597-17606.

31. Hizaddin, H. F.; Sarwono, M.; Hashim, M. A.; Alnashef, I. M.; Hadj-Kali, M. K. Coupling the capabilities of different complexing agents into deep eutectic solvents to enhance the separation of aromatics from aliphatics. J. Chem. Thermodyn. 2015, 84, 67-75.

32. Hadj-Kali, M. K.; Mulyono, S.; Hizaddin, H. F.; Wazeer, I.; El-Blidi, L.; Ali, E.; Ali Hashim, M.; AlNashef, I. M. Removal of thiophene from mixtures with n-heptane by selective extraction using deep eutectic solvents. Ind. Eng. Chem. Res. 2016, 55, 84158423. 
33. Hizaddin, H. F.; Hadj-Kali, M. K.; Ramalingam, A.; Hashim, M. A. Extractive denitrogenation of diesel fuel using ammonium-and phosphonium-based deep eutectic solvents. J. Chem. Thermodyn. 2016, 95, 164-173.

34. El-hoshoudy, A. N.; Soliman, F. S.; Mansour, E. M.; Zaki, T.; Desouky, S. M. Experimental and theoretical investigation of quaternary ammonium-based deep eutectic solvent for secondary water flooding. J. Mol. Liq. 294, No. 111621.

35. Liu, Y.; Yu, H.; Sun, Y.; Zeng, S.; Zhang, X.; Nie, Y.; Zhang. S.; Ji, X. Screening deep eutectic solvents for CO2 capture with COSMO-RS. Front. Chem. 2020, 8, No. 82.

36. Clarke, C. J.; Tu, W. C.; Levers, O.; Brohl, A.; Hallett, J. P. Green and sustainable solvents in chemical processes. Chem. Rev. 2018, 118, 747-800.

37. Wen, Q.; Chen, J. X.; Tang, Y. L.; Wang, J.; Yang, Z. Assessing the toxicity and biodegradability of deep eutectic solvents. Chemosphere 2015, 132, 63-69.

38. Alhadid, A.; Mokrushina, L.; Minceva, M. Design of deep eutectic systems: a simple approach for preselecting eutectic mixture constituents. Molecules 2020, 25, No. 1077.

39. Martins, M. A.; Pinho, S. P.; Coutinho, J. A. Insights into the nature of eutectic and deep eutectic mixtures. J. Solution Chem. 2019, 48, 962-982.

40. Alhadid, A.; Mokrushina, L.; Minceva, M. Modeling of solid-liquid equilibria in deep eutectic solvents: a parameter study. Molecules 2019, 24, No. 2334.

41. Abbott, A. P.; Ahmed, E. I.; Prasad, K.; Qader, I. B.; Ryder, K. S. Liquid pharmaceuticals formulation by eutectic formation. Fluid Phase Equilibr. 2017, 448, 2-8.

42. Klamt, A.; Eckert, F. COSMO-RS: a novel and efficient method for the a priori prediction of thermophysical data of liquids. Fluid Phase Equilibr. 2000, 172, 43-72.

43. Song, Z.; Zhang, J.; Zeng, Q.; Cheng, H.; Chen, L.; Qi, Z. Effect of cation alkyl chain length on liquid-liquid equilibria of \{ionic liquids + thiophene+ heptane $\}$ : COSMO-RS prediction and experimental verification. Fluid Phase Equilibr. 2016, 425, 244-251.

44. Abbott, A. P.; Capper, G.; Davies, D. L.; Rasheed, R. K.; Tambyrajah, V. Novel solvent properties of choline chloride/urea mixtures. Chem. Commun. 2003, 1, 70-71.

45. Guo, W.; Hou, Y.; Ren, S.; Tian, S.; Wu, W. Formation of deep eutectic solvents by phenols and choline chloride and their physical properties. J. Chem. Eng. Data 2013, 58, 866-872.

46. Crespo, E. A.; Silva, L. P.; Martins, M. A.; Fernandez, L.; Ortega, J.; Ferreira, O.; Sadowski, G.; Held, C.; Pinho, S. P.; Coutinho, J. A. Characterization and modeling of the liquid phase of deep eutectic solvents based on fatty acids/alcohols and choline chloride. Ind. Eng. Chem. Res. 2017, 56, 12192-12202. 
47. Silva, L. P.; Fernandez, L.; Conceição, J. H.; Martins, M. A.; Sosa, A.; Ortega, J.; Pinho, S. P.; Coutinho, J. A. Design and characterization of sugar-based deep eutectic solvents using conductor-like screening model for real solvents. ACS Sustain. Chem. Eng. 2018, 6, 10724-10734.

48. Abranches, D. O.; Larriba, M.; Silva, L. P.; Melle-Franco, M.; Palomar, J. F.; Pinho, S. P.; Coutinho, J. A. Using COSMO-RS to design choline chloride pharmaceutical eutectic solvents. Fluid Phase Equilibr. 2019, 497, 71-78.

49. Benguerba, Y.; Alnashef, I. M.; Erto, A.; Balsamo, M.; Ernst, B. A quantitative prediction of the viscosity of amine based DESs using S $\sigma$-profile molecular descriptors. J. Mol. Struct. 2019, 1184, 357-363.

50. Zhou, T.; Qi, Z.; Sundmacher, K. Model-based method for the screening of solvents for chemical reactions. Chem. Eng. Sci. 2014, 115, 177-185.

51. Zhang, Y.; Ji, X.; Lu, X. Choline-based deep eutectic solvents for CO2 separation: review and thermodynamic analysis. Renew. Sustain. Energy Rev. 2018, 97, 436-455.

52. Li, G.; Deng, D.; Chen, Y.; Shan, H.; Ai, N. Solubilities and thermodynamic properties of $\mathrm{CO} 2$ in choline-chloride based deep eutectic solvents. J. Chem. Thermodyn. 2014, 75, 5862.

53. Liu, X.; Gao, B.; Jiang, Y.; Ai, N.; Deng, D. Solubilities and thermodynamic properties of carbon dioxide in guaiacol-based deep eutectic solvents. J. Chem. Eng. Data 2017, 62, 1448-1455.

54. Chen, Y.; Ai, N.; Li, G.; Shan, H.; Cui, Y.; Deng, D. Solubilities of carbon dioxide in eutectic mixtures of choline chloride and dihydric alcohols. J. Chem. Eng. Data 2014, 59, 1247-1253.

55. Leron, R. B.; Caparanga, A.; Li, M. H. Carbon dioxide solubility in a deep eutectic solvent based on choline chloride and urea at $\mathrm{T}=303.15-343.15 \mathrm{~K}$ and moderate pressures. J. Taiwan Inst. Chem. Eng. 2013, 44, 879-885.

56. Leron, R. B.; Li, M. H. Solubility of carbon dioxide in a eutectic mixture of choline chloride and glycerol at moderate pressures. J. Chem. Thermodyn. 2013, 57, 131-136.

57. Leron, R. B.; Li, M. H. Solubility of carbon dioxide in a choline chloride-ethylene glycol based deep eutectic solvent. Thermochim. Acta 2013, 551, 14-19.

58. Benfenati, E.; Manganaro, A.; Gini, G. C. VEGA-QSAR: AI inside a platform for predictive toxicology. CEUR Workshop Proceedings, 2013, 1107, 21-28. 
59. Wang, J.; Song, Z.; Cheng, H.; Chen, L.; Deng, L.; Qi, Z. Computer-aided design of ionic liquids as absorbent for gas separation exemplified by $\mathrm{CO} 2$ capture cases. ACS Sustain. Chem. Eng. 2018, 6, 12025-12035.

60. Bechtel, S.; Song, Z.; Zhou, T.; Vidakovic-Koch, T.; Sundmacher, K. Integrated process and ionic liquid design by combining flowsheet simulation with quantum-chemical solvent screening. Comput. Aided Chem. Eng. 2018, 44, 2167-2172.

61. Perez-Salado Kamps, A.; Tuma, D.; Xia, J.; Maurer, G. Solubility of CO2 in the ionic liquid [bmim][PF6]. J. Chem. Eng. Data 2003, 48, 746-749.

62. Aki, S. N.; Mellein, B. R.; Saurer, E. M.; Brennecke, J. F. High-pressure phase behavior of carbon dioxide with imidazolium-based ionic liquids. J. Phys. Chem. B 2004, 108, 20355-20365.

63. Murrieta-Guevara, F.; Romero-Martinez, A.; Trejo, A. Solubilities of carbon dioxide and hydrogen sulfide in propylene carbonate, N-methylpyrrolidone and sulfolane. Fluid Phase Equilibr. 1988, 44, 105-115.

64. Gainar, I., Anitescu, G. The solubility of CO2, N2 and H2 in a mixture of dimethylether polyethylene glycols at high pressures. Fluid Phase Equilibr. 1995, 109, 281-289.

65. Sander, R. Compilation of Henry's law constants (version 4.0) for water as solvent. Atmos. Chem. Phys. 2015, 15, 4399-4981. 
Table 1. Statistical results of the obtained MLR for $\Delta T_{f}$.

\begin{tabular}{cccccc}
\hline Variables & Estimated coefficients & Standard error & tStat & F & p-value \\
\hline HB_don3 & 9.03 & 1.50 & 6.03 & 36.30 & $1.98 \times 10^{-6}$ \\
HB_acc3 & 2.90 & 1.13 & 2.56 & 6.55 & $1.60 \times 10^{-2}$ \\
V & -0.23 & 0.03 & -7.30 & 53.25 & $7.54 \times 10^{-8}$ \\
Intercept & 136.02 & 10.92 & 12.46 & - & $1.04 \times 10^{-12}$ \\
Model statistics: $\mathrm{R}^{2}=0.85$, adjusted $\mathrm{R}^{2}=0.83, \mathrm{RMSE}=16.8$ & & & \\
\hline
\end{tabular}

Table 2. Top 10 DES candidates screened according to the ranking of $\mathrm{AC} \times \mathrm{DE} \times 10^{3}$.

\begin{tabular}{cccccc}
\hline Ranking & HBD & ChCl: $\mathrm{HBD}$ & $\mathrm{AC} \times 10^{3}$ & $\mathrm{DE}$ & $\mathrm{AC} \times \mathrm{DE} \times 10^{3}$ \\
\hline $1^{*}$ & urea & $1: 2$ & 2.21 & 1.62 & 3.58 \\
2 & ethylenecyanohydrin & $1: 1$ & 2.33 & 1.49 & 3.46 \\
3 & ethylenecyanohydrin & $1: 2$ & 2.03 & 1.55 & 3.15 \\
4 & ethylenecyanohydrin & $1: 3$ & 1.90 & 1.56 & 2.96 \\
5 & pyruvicacid & $1: 1$ & 1.77 & 1.51 & 2.66 \\
6 & 1-(2-hydroxyethyl)imidazole & $1: 1$ & 1.75 & 1.48 & 2.59 \\
7 & cyanoaceticacid & $1: 1$ & 1.61 & 1.57 & 2.53 \\
8 & 4-pentyn-1-ol & $1: 1$ & 1.69 & 1.47 & 2.50 \\
9 & 4-pentyn-1-ol & $1: 3$ & 1.70 & 1.45 & 2.47 \\
$10 *$ & ethylene glycol & $1: 1.75$ & 1.57 & 1.53 & 2.40 \\
\hline
\end{tabular}

*: DESs that have been experimentally reported. 
Table 3. Comparison of the $H_{\mathrm{m}}$ of $\mathrm{CO}_{2}$ in the studied DESs at around $298.15 \mathrm{~K}$ with that in previously reported DESs and typical ionic liquids.

\begin{tabular}{|c|c|c|}
\hline Solvents & $H_{\mathrm{m}}(\mathrm{MPa} . \mathrm{kg} / \mathrm{mol})$ & Ref. \\
\hline Propylene carbonate & $0.78^{\mathrm{a}}$ & 63 \\
\hline Dimethyl ether of polyethylene glycol & $1.00^{\mathrm{a}}$ & 64 \\
\hline Water & $2.93^{\mathrm{a}}$ & 65 \\
\hline$[\mathrm{Bmim}]\left[\mathrm{BF}_{4}\right]$ & $0.94^{\mathrm{a}}$ & 62 \\
\hline$[\mathrm{Bmim}][\mathrm{TfO}]$ & $1.00^{\mathrm{a}}$ & 62 \\
\hline$[\mathrm{Bmim}]\left[\mathrm{Tf}_{2} \mathrm{~N}\right]$ & $1.06^{\mathrm{a}}$ & 62 \\
\hline$[\mathrm{Bmim}][\mathrm{DCA}]$ & $1.10^{\mathrm{a}}$ & 62 \\
\hline$[\mathrm{Bmim}]\left[\mathrm{PF}_{6}\right]$ & $1.19^{\mathrm{b}}$ & 61 \\
\hline$[\mathrm{Bmim}]\left[\mathrm{NO}_{3}\right]$ & $1.60^{\mathrm{a}}$ & 62 \\
\hline $\mathrm{ChCl}$ : ethylenecyanohydrin $(1: 2)$ & $0.99^{\mathrm{a}}$ & this work \\
\hline $\mathrm{ChCl}$ : ethylenecyanohydrin $(1: 3)$ & $1.09^{\mathrm{a}}$ & this work \\
\hline $\mathrm{ChCl}:$ urea $(1: 2)$ & $1.31^{\mathrm{c}}$ & 55 \\
\hline $\mathrm{ChCl}$ : glycerol $(1: 2)$ & $1.41^{\mathrm{c}}$ & 56 \\
\hline $\mathrm{ChCl}$ : ethylene glycol (1:2) & $1.84^{\mathrm{c}}$ & 57 \\
\hline DEHCl: guaiacol (1:5) & $2.25^{\mathrm{b}}$ & 53 \\
\hline DEHCl: guaiacol (1:4) & $2.33^{\mathrm{b}}$ & 53 \\
\hline ChCl: phenol $(1: 4)$ & $2.38^{\mathrm{b}}$ & 52 \\
\hline DEHCl: guaiacol (1:3) & $2.44^{\mathrm{b}}$ & 53 \\
\hline $\mathrm{ChCl}$ : phenol $(1: 2)$ & $2.47^{\mathrm{b}}$ & 52 \\
\hline ChCl: phenol (1:3) & $2.50^{\mathrm{b}}$ & 52 \\
\hline $\mathrm{ChCl}$ : triethylene glycol (1:4) & $2.56^{\mathrm{b}}$ & 52 \\
\hline $\mathrm{ChCl}$ : triethylene glycol (1:3) & $2.56^{\mathrm{b}}$ & 52 \\
\hline ChCl: 2,3-butanediol (1:4) & $2.59^{\mathrm{b}}$ & 54 \\
\hline ChCl: 1,2-propanediol (1:4) & $2.60^{\mathrm{b}}$ & 4 \\
\hline $\mathrm{ACCl}:$ guaiacol $(1: 5)$ & $2.63^{\mathrm{b}}$ & 53 \\
\hline $\mathrm{ChCl}$ : diethylene glycol (1:4) & $2.64^{\mathrm{b}}$ & 52 \\
\hline $\mathrm{ACCl}$ : guaiacol $(1: 4)$ & $2.75^{\mathrm{b}}$ & 53 \\
\hline $\mathrm{ChCl}$ : 1,2-propanediol (1:3) & $2.76^{\mathrm{b}}$ & 54 \\
\hline $\mathrm{ChCl}$ : guaiacol $(1: 5)$ & $2.79^{b}$ & 53 \\
\hline ACCl: guaiacol (1:3) & $2.79^{\mathrm{b}}$ & 53 \\
\hline $\mathrm{ChCl}$ : diethylene glycol (1:3) & $2.96^{\mathrm{b}}$ & 52 \\
\hline $\mathrm{ChCl}$ : guaiacol (1:4) & $2.98^{\mathrm{b}}$ & 53 \\
\hline ChCl: guaiacol (1:3) & $3.10^{\mathrm{b}}$ & 53 \\
\hline $\mathrm{ChCl}$ : 1,4-butanediol (1:3) & $3.12^{\mathrm{b}}$ & 54 \\
\hline $\mathrm{ChCl}$ : 1,4-butanediol (1:4) & $3.21^{\mathrm{b}}$ & 54 \\
\hline ChCl: 2,3-butanediol (1:3) & $3.32^{\mathrm{b}}$ & 54 \\
\hline
\end{tabular}

a. $H_{\mathrm{m}}$ at $298.15 \mathrm{~K}$; b: $H_{\mathrm{m}}$ at $293.15 \mathrm{~K}$; c. $H_{\mathrm{m}}$ at $303.15 \mathrm{~K}$. 


\section{Figure captions}

Figure 1. Systematic DES screening method proposed in this work.

Figure 2.Illustration of a typical DES phase diagram $\left(T_{\mathrm{f}, \mathrm{A}}\right.$ and $T_{\mathrm{f}, \mathrm{B}}$ : freezing points of individual component $\mathrm{A}$ and $\mathrm{B} ; T_{\mathrm{f}, \mathrm{im}}$ and $T_{\mathrm{f}, \mathrm{im}}$ : ideally interpolated temperature at the assumed maximum and the practical eutectic composition; $T_{\mathrm{me}}$ and $T_{\mathrm{e}}$ : estimated maximum and the practical eutectic temperature; $x_{\mathrm{e}}$ : the eutectic composition).

Figure 3.Comparison of the experimentally determined and MLR correlated $\Delta T_{\mathrm{f}}$ of ChClbased DESs.

Figure 4.Grade table of the five EHS-relevant properties of HBDs illustrated with some representatives.

Figure 5. Comparison of experimentally determined and COSMO-RS predicted $H_{x}$ of $\mathrm{CO}_{2}$ in different DESs.

Figure 6.COSMO-RS derived $\mathrm{AC}$ and DE of different DESs obtained after the EHS screening.

Figure 7. Solubility of $\mathrm{CO}_{2}$ in the prepared $\mathrm{ChCl}$ : ethylenecyanohydrin DESs as a function of pressure (symbols, experimental; lines, linear fit). 
Figure 1.Systematic DES screening method proposed in this work.

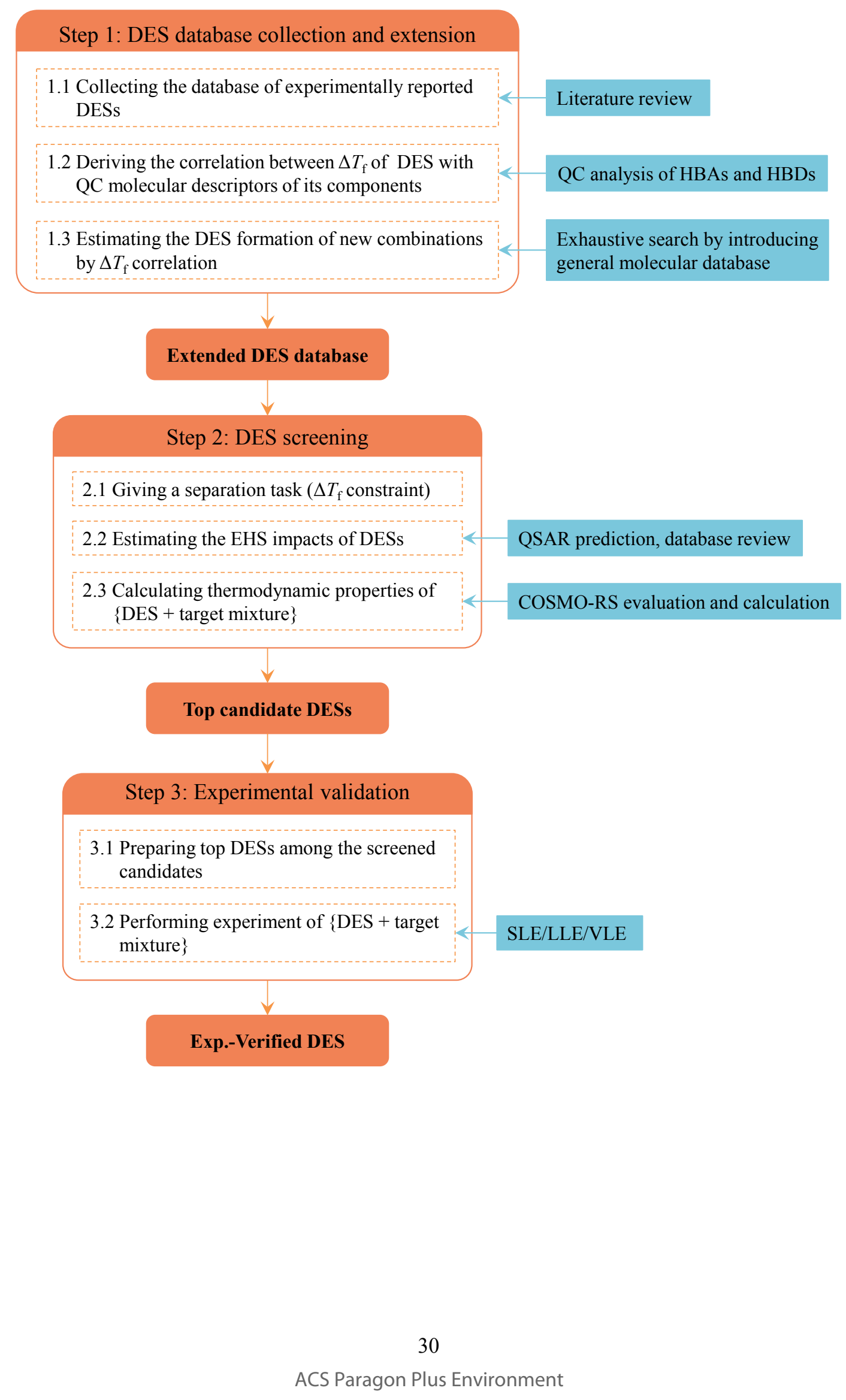


Figure 2.Illustration of a typical DES phase diagram $\left(T_{\mathrm{f}, \mathrm{A}}\right.$ and $T_{\mathrm{f}, \mathrm{B}}$ : freezing points of individual component $\mathrm{A}$ and $\mathrm{B} ; T_{\mathrm{f}, \mathrm{im} *}$ and $T_{\mathrm{f}, \mathrm{im}}$ : ideally interpolated temperature at the assumed maximum and the practical eutectic composition; $T_{\mathrm{me}}$ and $T_{\mathrm{e}}$ : estimated maximum and the practical eutectic temperature; $x_{\mathrm{e}}$ : the eutectic composition).

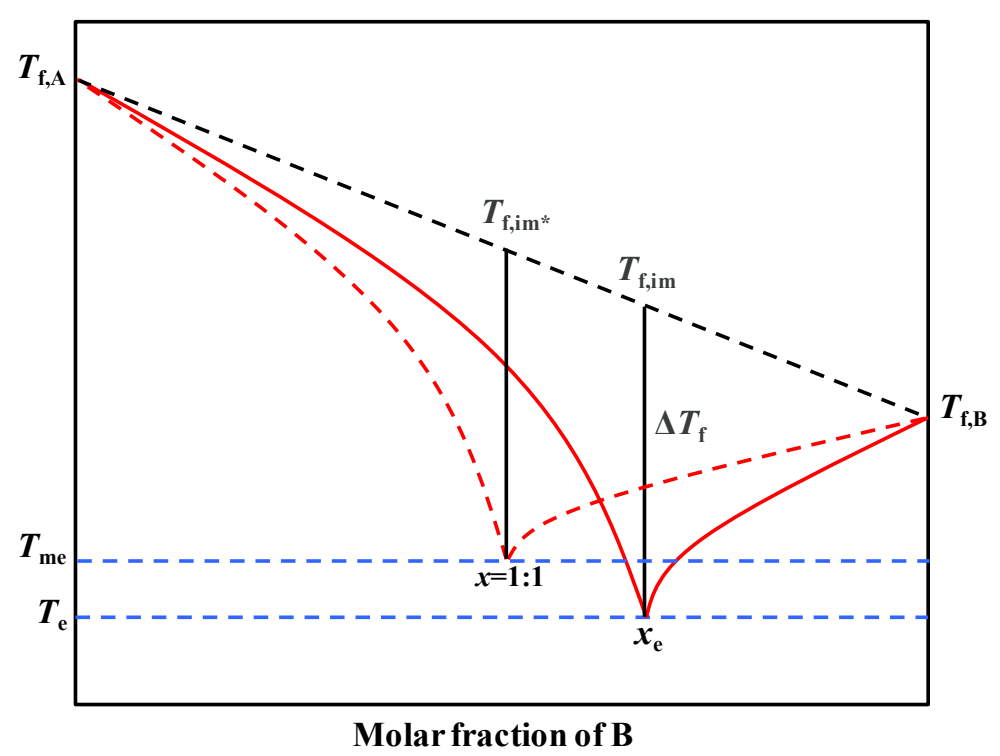


Figure 3. Comparison of the experimentally determined and MLR correlated $\Delta T_{\mathrm{f}}$ of ChClbased DESs.

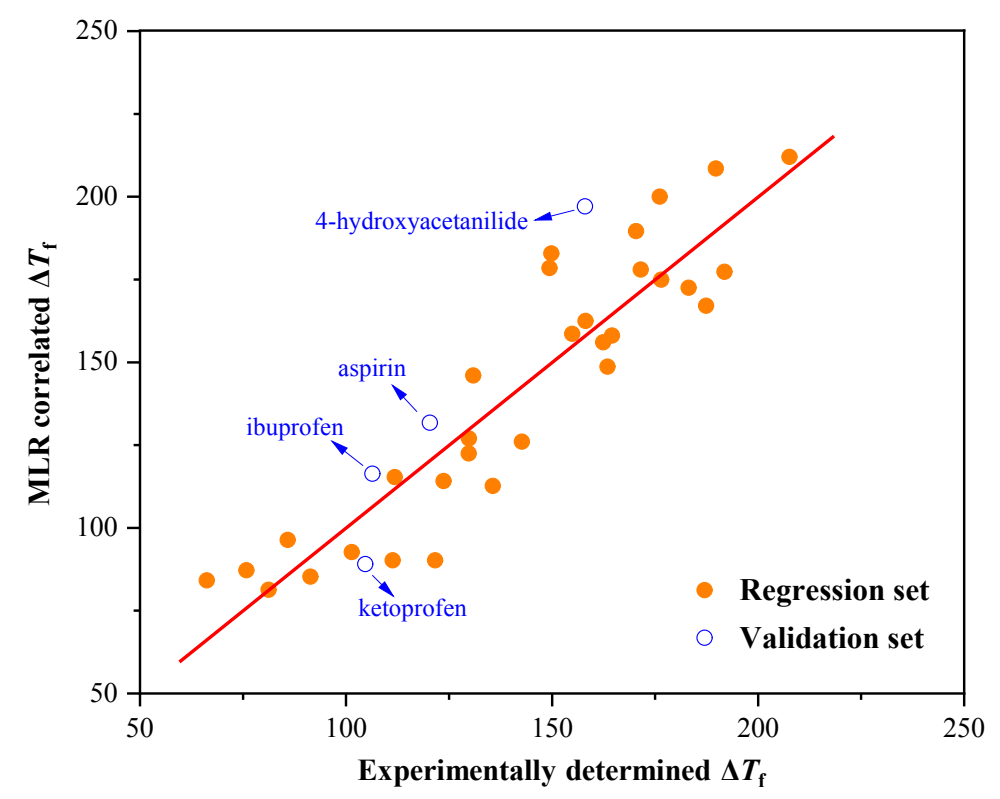


Figure 4.Grade table of the five EHS-relevant properties of HBDs illustrated with some representatives.

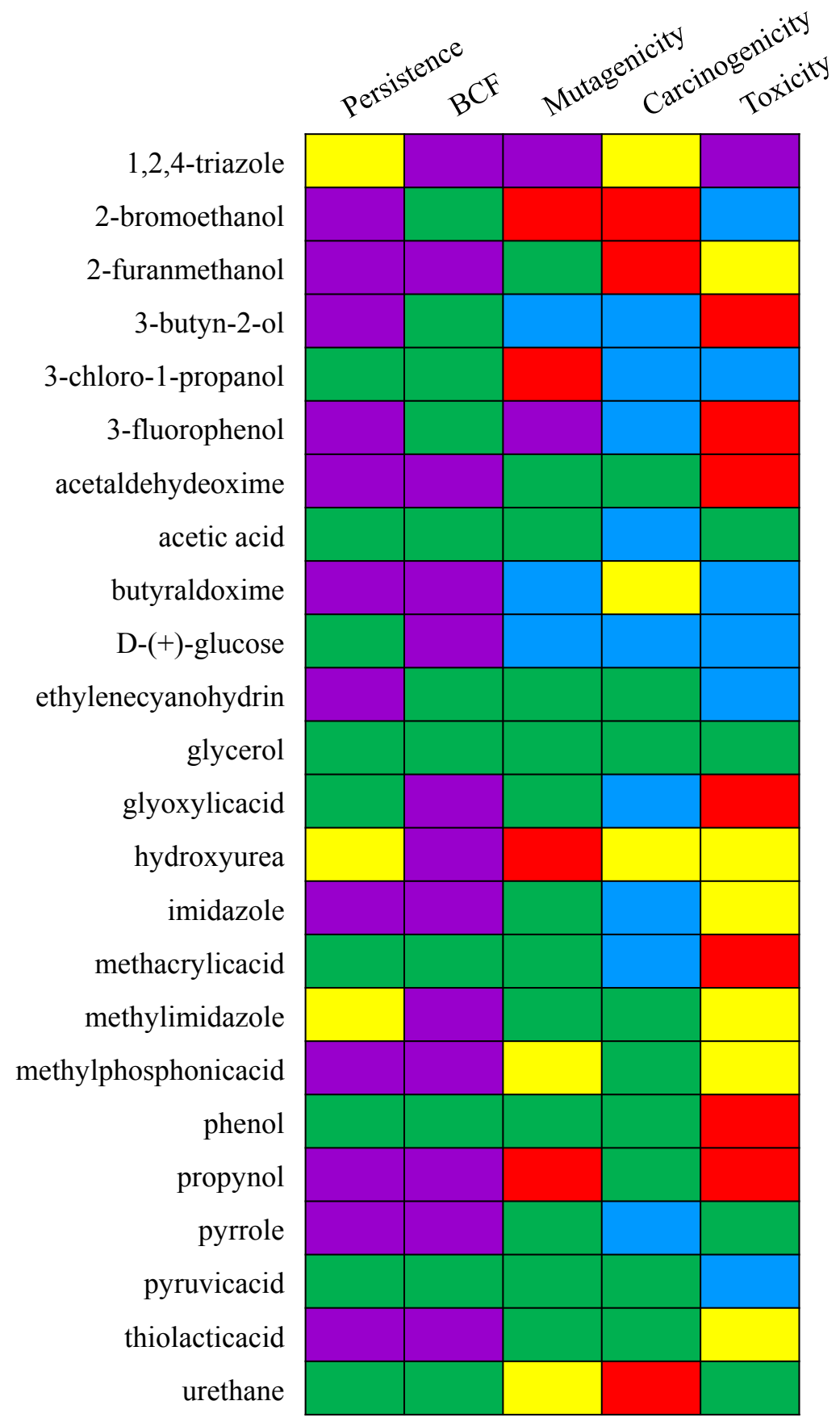


Figure 5.Comparison of experimentally determined and COSMO-RS predicted $H_{x}$ of $\mathrm{CO}_{2}$ in different DESs.

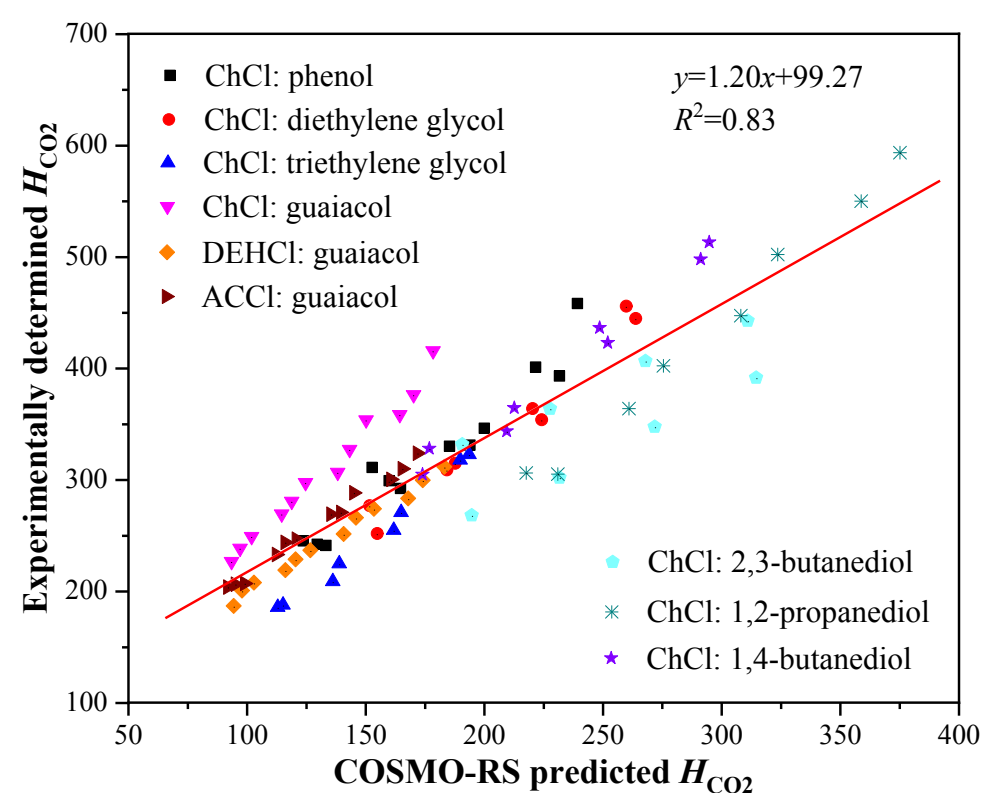


Figure 6.COSMO-RS derived AC and DE of different DESs obtained after EHS screening.

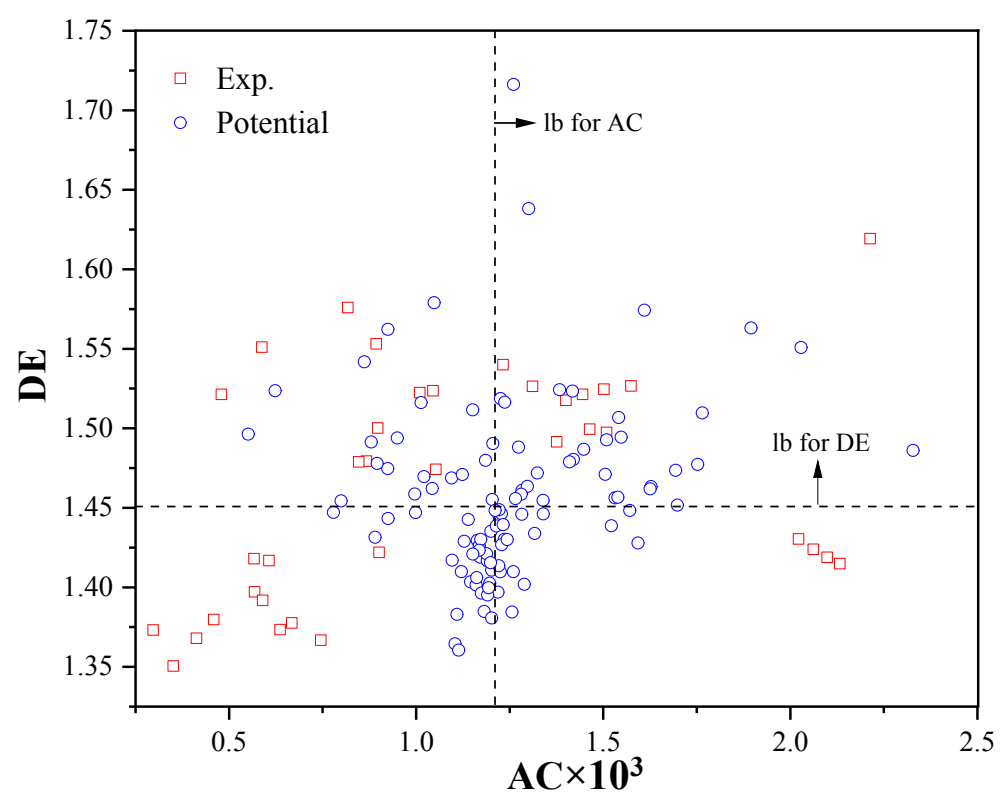


Figure 7. Solubility of $\mathrm{CO}_{2}$ in the prepared $\mathrm{ChCl}$ : ethylenecyanohydrin $\mathrm{DESs}$ as a function of pressure (symbols, experimental; lines, linear fit).

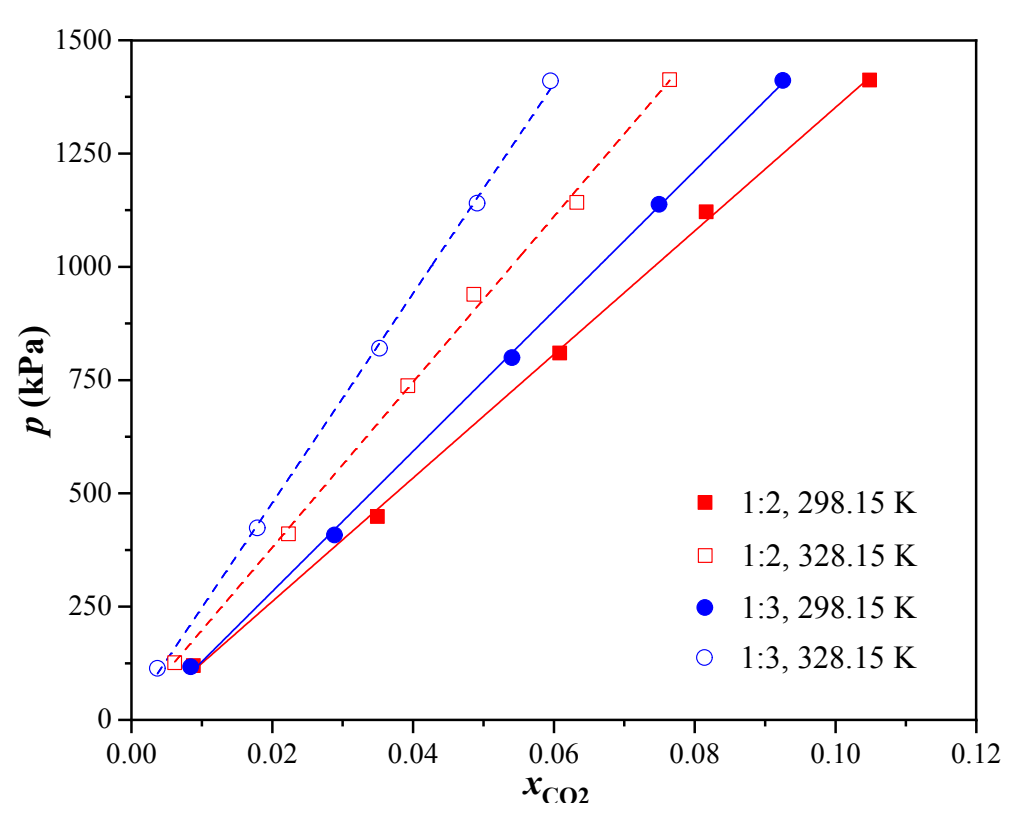


2

3

4

5

6

7

8

9

10

11

12

13

14

15

16

17

18

\section{Table of Contents}

\section{DES database extension EHS properties analysis}
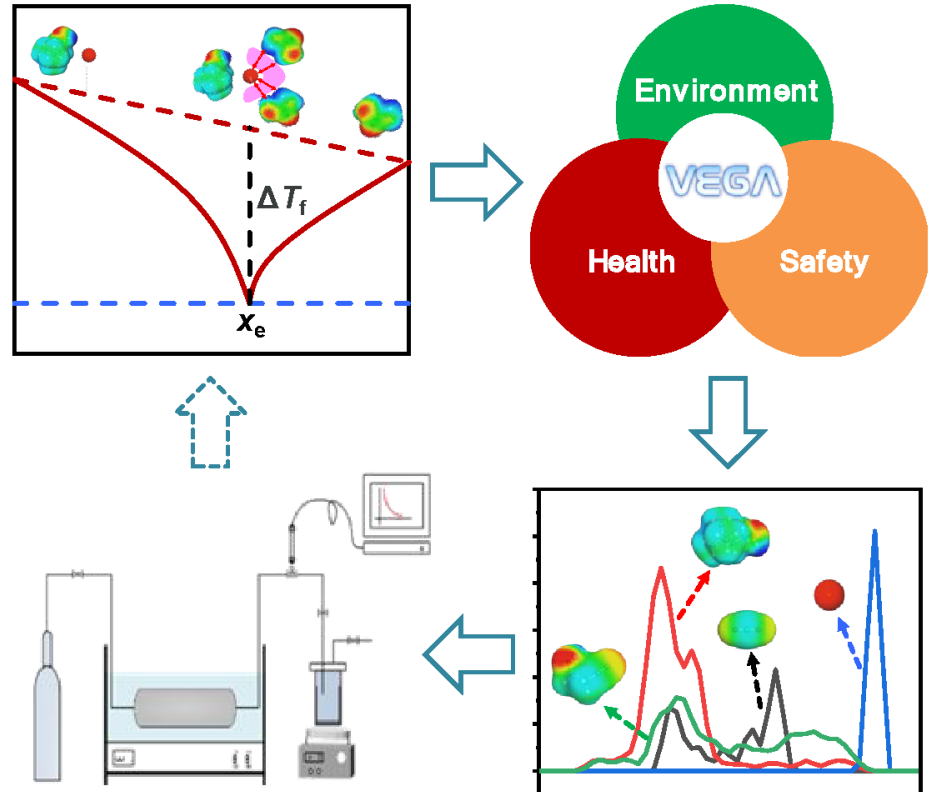

Experimental validation

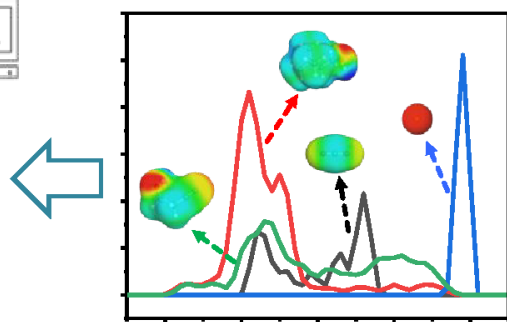

Thermodynamic prediction

Synopsis: Rationally screened deep eutectic solvents possess great potential as efficient and sustainable media for various separation process. 